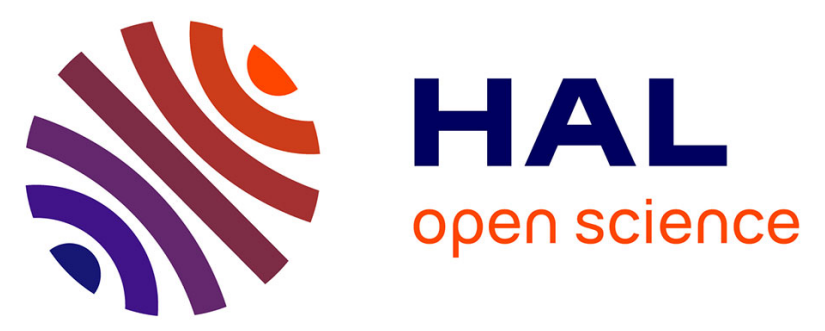

\title{
Phenomenology, socio-demographic factors and outcome upon discharge of manic and mixed episodes in hospitalized adolescents
}

\author{
Julie Brunelle, Angèle Consoli, Marie-Laure Tanguy, Christophe Huynh, \\ Didier Perisse, Emmanuelle Deniau, Jean-Marc Guilé, Priscille Gérardin, \\ David Cohen
}

\section{To cite this version:}

Julie Brunelle, Angèle Consoli, Marie-Laure Tanguy, Christophe Huynh, Didier Perisse, et al.. Phenomenology, socio-demographic factors and outcome upon discharge of manic and mixed episodes in hospitalized adolescents. European Child and Adolescent Psychiatry, 2009, 18 (3), pp.185-193. 10.1007/s00787-008-0715-7 . hal-00486568

\section{HAL Id: hal-00486568 https://hal.science/hal-00486568}

Submitted on 26 May 2010

HAL is a multi-disciplinary open access archive for the deposit and dissemination of scientific research documents, whether they are published or not. The documents may come from teaching and research institutions in France or abroad, or from public or private research centers.
L'archive ouverte pluridisciplinaire HAL, est destinée au dépôt et à la diffusion de documents scientifiques de niveau recherche, publiés ou non, émanant des établissements d'enseignement et de recherche français ou étrangers, des laboratoires publics ou privés. 
Julie Brunelle Angèle Consoli Marie-Laure Tanguy

Christophe Huynh

Didier Périsse

Emmanuelle Deniau

Jean-Marc Guilé

Priscille Gérardin

David Cohen

\section{Phenomenology, socio-demographic factors and outcome upon discharge of manic and mixed episodes in hospitalized adolescents}

\author{
A chart review
}

Received: 12 February 2008

Accepted: 6 July 2008

Published online: 6 January 2009
Abstract Background The existence of bipolar disorder type I (BD-I) during adolescence is now clearly established whereas there are still some controversies on $\mathrm{BD}-\mathrm{II}$ and BD-NOS diagnosis, mainly in Europe (O'Dowd in $\mathrm{Br}$ Med J 29, 2006). Little is known on the phenomenology and potential short-term prognosis factors of bipolar episodes in this age population. In particular, very few studies examine this issue on inpatients in the European context of free access to care. Objective To describe the phenomenology of acute manic and mixed episodes in hospitalized adolescents and to analyse potential predictive factors associated with clinical improvement at discharge and length of hospitalization. Methods A total of 80 subjects, aged $12-20$ years, consecutively hospitalized for a manic or mixed episode. Sociodemographic and clinical data were extracted by reviewing patients' charts. We used a multivariate analysis to evaluate shortterm outcome predictors. Results The sample was characterized by severe impairment, high rates of psychotic features $(N=50$,
$62.5 \%)$, a long duration of stay (mean 80.4 days), and an overall good improvement ( $86 \%$ very much or much improved). Thirtythree $(41.3 \%)$ patients had a history of depressive episodes, 13 $(16.3 \%)$ had manic or brief psychotic episodes but only 3 (3.7\%) had a history of attention deficit/ hyperactivity disorders. More manic episodes than mixed episodes were identified in subjects with mental retardation (MR) and in subjects from migrant and/or low socio-economic families. Overall severity and female gender predicted better improvement in GAF scores. Poor insight and the existence of psychotic features predicted longer duration of stay. Conclusion These results suggest that severe manic and mixed episodes in adolescents with BD-I need prolonged inpatient care to improve and that socio-cultural factors and MR should be examined more closely in youth with BD.

Key words bipolar disorder type I - acute episode adolescent - prognosis socio-cultural factors 


\section{Introduction}

Interest in juvenile mania is recent despite the seminal description in Kraepelin's monograph [37] and several retrospective studies revealing that $20-60 \%$ of adults with bipolar disorder (BD) had their first symptoms before the age of 20 years [30, 41, 48]. Despite the fact that diagnosing BD during adolescence remains difficult $[7,8]$ and that controversies still remain concerning the existence of BD-NOS and BD-II in this age population, mainly in Europe [44], typical BD-I in teens is no longer controversial [11]. In adolescents, $\mathrm{BD}$ is a frequent diagnosis but $\mathrm{BD}-\mathrm{I}$ is much more rare with lifetime prevalence rates of 1 and $0.1 \%$, respectively $[39,34]$.

As compared to adult-onset $\mathrm{BD}$, the phenomenology of acute manic episodes in adolescents can be summarized as follows: (1) more mixed episodes than purely manic ones, with frequent aggressive behaviors and irritability $[25,43,46] ;$ (2) the presence of psychotic features in $30-50 \%$ of the cases [9]; (3) high rates of comorbidities including ADHD, substance abuse, conduct and anxiety disorders [3, 14, 24, 49] and (4) a rapid cycling profile more often observed [5, 38]. However, regarding rates and severity of psychotic features, inconsistent results are found in the literature. Patel et al. [46], in a comparative study of clinical characteristics of early-onset ( $<18$ years) versus typical-onset (20-30 years) $\mathrm{BD}$, showed that typical-onset patients were rated with more severe psychotic features than early-onset patients whereas other authors found the opposite $[10,20]$. In the largest study published so far that included 438 children and adolescent with bipolar spectrum disorder (14.8\% inpatients only), the prevalence rate of psychotic symptoms and mixed polarity was 38 and $34 \%$, respectively [2].

Several prospective studies have been conducted on the course of illness and long-term prognosis of a manic episode in adolescents but few exhibit results on the determinants of short-term outcome. To summarize, mixed polarity, low socioeconomic status (SES), young age at onset, previous affective episode, psychosis and female sex were associated at least in one study with a poorer outcome [5, 18, 27, 29, 52]. Furthermore, in the US, inpatient treatment tends to be shorter and shorter (median lenght of stay for BD in 2000 is 5.6 days) due to economic pressures [12], which leads to a bias in short-term prognosis studies. As underlined by Strober et al. [53], observational data are sparse in the literature on BD in youths despite their great importance for assessment of prognosis and prospective long-term studies. In prospective studies on adults with $\mathrm{BD}$, longer duration of the intake episode, depressive or mixed polarity of the intake episode and substance use comorbidity have been identified as factors associated with greater morbidity [31, 32].

The current report is the first step of a follow-up study on youth hospitalized for an acute manic or mixed episode during a 10-year period (1993-2003) in a University hospital that serves a population of 8 10 million people. It aims to describe the phenomenology of acute manic and mixed episodes in this sample and to look for potential outcome predictors of these BP-I adolescents inpatients. To our knowledge, this is one of the first European reports on this issue on a sample of inpatients. Given the tendency of using $\mathrm{BD}$ as a broad spectrum including BD types I and II, paediatric BD and some borderline subjects [1] as well as the tendency to exclude patients with mental retardation (MR) from clinical studies, we aimed to focus on a sample of patients admitted for an acute manic or mixed episode, with severe impairement leading to hospitalization with no exclusion criteria. We assume that this sample would be representative of one end of the $\mathrm{BD}$ spectrum, to avoid confusion in the definition of bipolarity in youths.

Using a retrospective design, this report describes the sociodemographic and clinical data of the sample and the factors associated with short-term prognosis, defined as clinical improvement and length of hospitalization. We hypothesized that clinical severity, presence of psychotic features, low SES and/or MR would be associated with prognosis at discharge.

\section{Methods}

\section{Subjects}

By reviewing patient charts and staff reports, we systematically looked for all children and adolescents consecutively hospitalized for an acute manic or mixed episode between January 1993 and December 2003 at the Pitié-Salpêtrière Hospital, a University teaching hospital in Paris area that realizes $30-50 \%$ of all inpatients stay in child and adolescent psychiatry. During the study period, out of 4,165 inpatients, 120 subjects were hospitalized with a discharge diagnosis of $\mathrm{BD}$, schizoaffective or schizophreniform disorder, brief psychotic episode, manic episode, mixed episode and BD NOS. Two experienced child and adolescent psychiatrists of the department who had been the treating clinicians for some of the subjects but not all, reviewed the charts and selected all cases $(N=80)$ meeting a DSM IV discharge diagnosis of BD-1 (manic or mixed episode). No a priori exclusion criteria such as MR were used. For descriptive purposes, 
the number of subjects by year of hospitalization is indicated in Fig. 1. As previously mentioned, this report was a preliminary study of a follow up one. Thirty-two subjects (40\%) of the current sample could have been traced and evaluated at this point of the study. They were administered the diagnostic interview for genetic studies (DIGS) [19]. The DIGS confirmed that the index episode diagnosis was manic or mixed in all of them. The study was conducted according to the hospital ethics committee regulation.

\section{Procedures and variables}

For description of the index episode, we restrospectively reviewed charts (clinician and nurse notes) from the hospitalization period. All information pertaining to the identity of the subjects was removed. Selected data included sociodemographic data [gender, age at admission, parental origins, socio-economic status (SES)], past personal and family psychiatric history recorded at intake with a semi structured interview [55] and provided by the patients themselves when their clinical state allowed it and/or their parents (or care persons). Past psychiatric history was confirmed using the DIGS for the 32 subjects already evaluated at follow up. Clinical data reviewed were the type of episode (manic or mixed) and the type of onset [acute ( $<10$ days) or not], duration of hospitalization, presence of psychotic features (delusions and/or hallucinations as described in the DSM IV), the clinical global impression scale-severity of

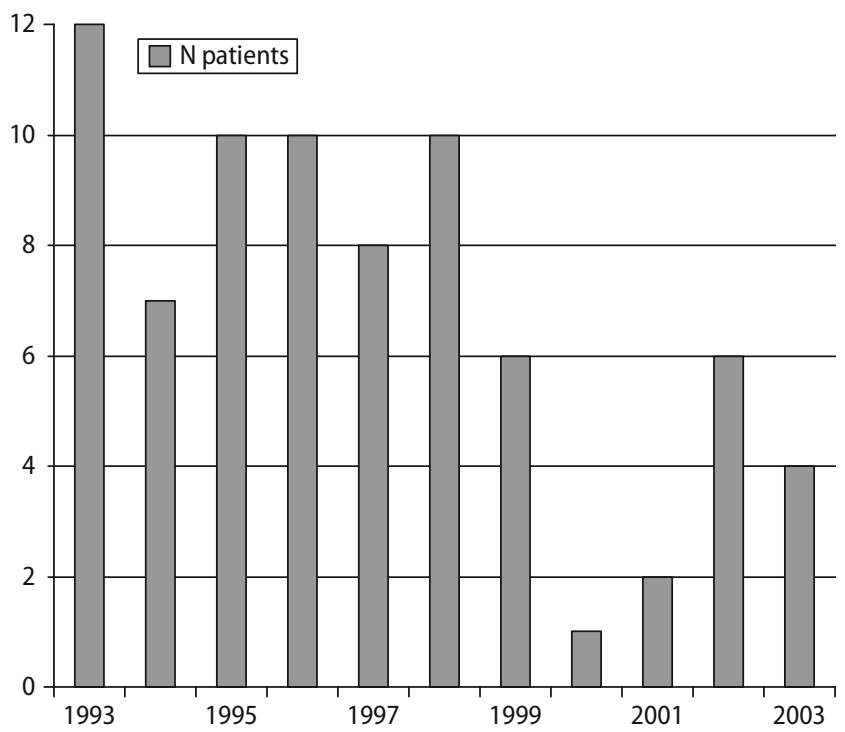

Fig. 1 Number of patients per year of hospitalization included during the study period (1993-2003). The notable decrease in admission of bipolar youths in 2000 and 2001 is related to the fact that 15 adolescent inpatients beds were unavailable during these 2 years illness (CGI-S) [15] and the global assessment of functioning scale (GAF) [21] that are both systematically scored at admission and discharge. Charts were also reviewed by the investigator, a third not treating psychiatrist, with respect to psychiatric symptoms at intake using the brief psychiatric rating scale (BPRS) [6], the Young mania rating scale (YMRS) [56], the Montgomery and Asberg depression rating scale (MADRS). A confirmatory inter-rater reliability study was performed on the YMRS, the BPRS and the MADRS in a sub-sample of ten randomly selected charts: intraclass correlations were $0.83,0.64$, and 0.45 , respectively. Therefore, we considered invalid to keep MADRS scores in the analysis. Because the cases were selected for review on the basis of the presence of a of BD-1 diagnosis, researchers could not be blind to the diagnosis. Mental retardation was recorded and defined by global IQ, verbal IQ or performance IQ < 70 (WISC III and WISC IV). When no cognitive evaluation was done during the stay because of clinical impairment $(N=38)$, subjects were identified as having MR according to the follwing definition of the American Association on Intellectual and Developemental Disabilities: Intellectual disability is a disability characterized by significant limitation both in intellectual functioning and in adaptative behavior as expressed in conceptual, social and practical adaptive skills. This disability originates before the age of 18 [42]. To assess short-term outcome, we selected two variables: duration of stay (days) and global clinical improvement measured by $\triangle \mathrm{GAF}$ (GAF at dischargeGAF at intake). Comorbid diagnoses were also reviewed but for this issue no systematic clinical semi-structured interview is used in current practice in the departement.

\section{Statistical analysis}

For clinical and socio-demographic variables of the total sample, we used classic descriptive statistics. Manic and mixed patients were compared using Student's $t$ tests for continuous variables and Chi-square or Fisher exact tests for categorical variables. Variables included in the univariate analysis to identify predictors of longer duration of stay and clinical improvement ( $\triangle \mathrm{GAF})$ were: age, sex, SES, father's origin, mother's origin, polarity of the episode, type of onset, psychosis, MR, BPRS (global score and each subscore), YMRS (global score and each subscore), CGI-severity and GAF score at intake. A stepwise multivariable linear regression analysis was then used to identify predictors of outcome upon discharge. Variables included in the model were univariate predictors with $P$ value $<0.05$. Two-tailed values of $P<0.05$ were considered statistically significant. All 
analyses were performed with the SAS software version 8.2 (SAS Institute, Cary, NC).

\section{Results}

\section{Socio-demographic and clinical characteristics of the sample}

The sample was composed of 45 females and 35 males with a mean age of $15.7( \pm 1.9)$ years (range 12-19). The socio-demographic and clinical characteristics of the sample are summarized in Table 1.

We found past psychiatric history in 68 subjects $(85 \%)$. In 33 of them (41.3\%), depressive episodes were identified. Two subjects $(2.5 \%)$ had presented a previous manic episode and 11 patients (13.7\%) had a previous brief psychotic episode. Three adolescents (3.7\%) had suffered from ADHD during childhood but it was always associated with concurrent disor- ders (conduct disorder, substance abuse or depression).

Previous family psychiatric history was mentioned in the history interview for 50 subjects $(62.5 \%)$. Ten subjects $(12.5 \%)$ had a family history of $\mathrm{BD}$ - seven $(8.75 \%)$ at first degree and three $(3.7 \%)$ at second degree. Thirty patients (37.5\%) reported at least one member of their family having a depressive disorder and $10(12.5 \%)$ had at least one member of their family with a psychotic disorder not specified.

As shown in Table 1, 49 adolescents presented with a manic episode and 31 with a mixed episode. Thirty subjects (37.5\%) reported an acute onset of the episode ( $\leq 10$ days). Psychotic features were found in 50 patients $(62.5 \%)$. Mean IQ was in the low range of normality [mean IQ $=83.4( \pm 23.4)$ ] and 17 subjects $(21.3 \%)$ had MR. Clinical severity scores, as assessed on the different scales at admission, confirmed that the sample was composed of severely impaired patients representing one end of the BD spectrum. De-

Table 1 Clinical and socio-demographic characteristics of youths hospitalized from 1993 to 2003 for acute manic and mixed episodes in a University Hospital $(N=80)$

\begin{tabular}{|c|c|c|c|}
\hline & Total $(N=80)$ & Manic episode $(N=49)$ & Mixed episode $(N=31)$ \\
\hline \multicolumn{4}{|l|}{ Socio-demographic characteristics } \\
\hline Sex & $45 \mathrm{~F}, 35 \mathrm{M}$ & $27 \mathrm{~F}, 22 \mathrm{M}$ & $18 \mathrm{~F}, 13 \mathrm{M}$ \\
\hline Age $($ mean $\pm S D)$ & $15.67 \pm 1.89$ & $15.65 \pm 1.9$ & $15.74 \pm 1.87$ \\
\hline Socio-economic status: $N(\%)$ good and middle & $50(63.3)$ & $26(53)^{*}$ & $24(77.4)^{*}$ \\
\hline Paternal origin: $N(\%)$ migrants $^{\mathrm{a}}$ & $34(44.2)$ & $27(55)^{*}$ & $10(32.2)^{*}$ \\
\hline Maternal origin $N(\%)$ migrants & $33(43.4)$ & $25(51)$ & $12(38.7)$ \\
\hline Both parents origin: $N(\%)$ migrants & $38(47.5)$ & $19(38.8)$ & $9(29)$ \\
\hline \multicolumn{4}{|l|}{ Previous psychiatric history } \\
\hline Personal history: $N(\%)$ & $68(85)$ & $42(85.7)$ & $26(83.9)$ \\
\hline Family history: $N(\%)$ & $50(62.5)$ & $30(61.2)$ & $20(64.5)$ \\
\hline Total IQ $\left(\right.$ mean \pm SD) ${ }^{\mathrm{b}}$ & $83.4 \pm 23.4$ & $78.3 \pm 23.3$ & $100.7 \pm 21.5$ \\
\hline Verbal IQ $(\text { mean } \pm S D)^{c}$ & $89.9 \pm 22.2$ & $87.2 \pm 22.3$ & $96.2 \pm 20.6$ \\
\hline Performance IQ (mean $\pm S D)^{d}$ & $83.9 \pm 24.8$ & $79.3 \pm 25.7$ & $95.2 \pm 18.9$ \\
\hline Mental retardation: $N(\%)$ & $17(21.3)$ & $14(28.6)^{*}$ & $3(9.6)^{*}$ \\
\hline \multicolumn{4}{|l|}{ Clinical characteristics } \\
\hline Acute onset ( $\leq 10$ days): $N$ (\%) & $30(37.5)$ & $20(40.8)$ & $10(32.2)$ \\
\hline Psychotic features: $N(\%)$ & $50(62.5)$ & $27(55)$ & $23(74.2)$ \\
\hline Catatonic features: $N(\%)$ & $4(5)$ & $2(4)$ & $2(6.4)$ \\
\hline Mental retardation: $N(\%)$ & $17(21.3)$ & $14(28.6)$ & $3(9.6)$ \\
\hline Duration of stay, days (mean \pm SD) (range) & $80.4 \pm 50.7(17-245)$ & $81.3 \pm 52.3(17-245)$ & $77.4 \pm 47.5 s(18-199)$ \\
\hline \multicolumn{4}{|l|}{ Scores at admission } \\
\hline GAF (mean $\pm \mathrm{SD}$ ) [range] & $23 \pm 7.9[10-40]$ & $23 \pm 7.7[10-40]$ & $22.9 \pm 7.7[10-40]$ \\
\hline CGI-S: $N(\%)$ severely/extremely ill & $61(76.3)$ & $38(77.5)$ & $23(74.2)$ \\
\hline BPRS (mean \pm SD) & $63.3 \pm 15.0$ & $62.9 \pm 12.8$ & $62.2 \pm 14.7$ \\
\hline YMRS (mean \pm SD) & $22.2 \pm 6.5$ & $22.2 \pm 6$ & $22.1 \pm 6$ \\
\hline \multicolumn{4}{|l|}{ Scores at discharge } \\
\hline $\mathrm{GAF}($ mean $\pm \mathrm{SD})$ & $64 \pm 14.4$ & $64.2 \pm 12.7$ & $64.2 \pm 12.9$ \\
\hline CGI-I: very much improved $N(\%)$ & $18(22.4)$ & $12(24.4)$ & $6(19.3)$ \\
\hline much improved $N(\%)$ & $51(63.8)$ & $28(57)$ & $23(74)$ \\
\hline minimally improved $N(\%)$ & $11(13.8)$ & $9(18.4)$ & $2(6.5)$ \\
\hline
\end{tabular}

IQ intellectual quotient, GAF global assessment of functioning scale, CGI-S clinical global impressions-severity of illness scale, BPRS brief psychiatric rating scale, YMRS Young Mania rating scale, MADRS montgomery and asberg depression rating scale, CGI-I clinical global impressions-improvement

$* P<0.05$

${ }^{\mathrm{a}}$ Migrants: from all countries but France and DOM-TOM; ${ }^{\mathrm{b}} N=31 ;{ }^{\mathrm{C}} \mathrm{N}=42 ;{ }^{\mathrm{d}} N=42$ 
spite prolonged hospitalization in many cases (minimum stay $=17$ days), it should be highlighted that all patients improved clinically during their stay (Table 1). Pharmacological treatments and comorbid disorders were also reviewed but analysis of these data are not completed yet.

\section{Comparison of subjects with manic versus mixed episodes}

As expected, adolescents with mixed episodes had more severe scores on depressive symptoms as evidenced by BPRS guilt and depression subscores [3.4 $( \pm 2)$ vs. $1.7( \pm 1.5), P=0.001 ; 4.4( \pm 1.4)$ vs. $2.7( \pm 1.7)$, $P=0.0001$; respectively]. Similarly, adolescents with manic episode had more agressive symptoms as evidence on the YMRS agressive subscore, BPRS hostility and non-cooperation subscores $[1.6( \pm 1.3)$ vs. 0.9 ( \pm 1.2$), P=0.04 ; 4.4( \pm 2.0)$ vs. $3.4( \pm 1.9), P=0.04 ; 3.6$ $( \pm 1.7)$ vs. $2.7( \pm 1.5), P=0.02$; respectively).

Among other variables that were significantly different, we listed MR, origin of the father and SES. They were more manic episodes among adolescents with MR (88 vs. $57 \%$ in adolescents without MR, $P=0.04$ ), among adolescents whose fathers were immigrants from Africa and other non-EU countries (79 vs. $56 \%$ in adolescents from non-immigrants fathers, $P=0.02)$, and among families with low SES (85 vs. $64 \%$ in families with middle SES and $46 \%$ with high SES, $P=0.01$ ).

\section{Predictors of $\triangle \mathrm{GAF}$ and length of hospitalization}

Predictors of length of hospitalization and $\triangle G A F$ at the time of discharge from the hospital in acute BD-I in youths were tested. We tested the following dependent variables: age, sex, SES, father's ethnic origin, mother's ethnic origin, episode polarity (manic/mixed), type of onset (acute or subacute), presence of psychotic features, MR, BPRS (global and subscores), YMRS (global and subscores), GCI-S and GAF scores at intake.

Table 2 summarizes the significant results of the univariate and multivariate regression analysis for each variable. When outcome was assessed by improvement of GAF scores, overall severity (YMRS total score, YMRS content score) predicted a better improvement among clinical dependant variables, whereas among socio-demographic variables, only female sex predicted better improvement. When assessing prognosis by length of hospitalization, only poor insight and psychotic features predicted longer duration of stay (YMRS insight and language/thought disorder subscores).
Table 2 Prognostic factors associated with acute episode of bipolar type I disorder in youths

\begin{tabular}{ll}
\hline Variables associated with longer length of hospitalization & $P$ value \\
\hline Univariate analysis & \\
Maternal origin & 0.03 \\
BPRS mannerism and posturing score & 0.02 \\
BPRS hallucination score & 0.02 \\
BPRS total score & 0.0008 \\
YMRS language/thought disorder score & 0.02 \\
YMRS insight score & 0.002 \\
CGI-S & 0.03 \\
Multivariate analysis & \\
YMRS language/thought disorder score & 0.02 \\
YMRS insight score & 0.002 \\
\hline Variables associated with improvement of GAF & $P$ value \\
\hline Univariate analysis & \\
Female & 0.02 \\
BPRS conceptual disorganisation score & 0.004 \\
YMRS language/thought disorder score & 0.005 \\
YMRS content score & 0.02 \\
YMRS appearance score & 0.03 \\
YMRS total score & 0.03 \\
Multivariate analysis & 0.02 \\
Female & 0.02 \\
YMRS content score & 0.03 \\
YMRS total score &
\end{tabular}

GAF global assessment of functioning scale, CGI-S clinical global impressionsseverity, BPRS brief psychiatric rating scale, YMRS Young mania rating scale

\section{Discussion}

\section{Limitations and strengths}

The major limitation of this study is its retrospective design, adressing the question of intake diagnosis accuracy, given the absence of systematic use of a semi-structured clinical diagnosis instrument in everyday practice in the department. In particular, data regarding comorbidity and history should be regarded with caution as retrospective design usually underestimates them. As previously stated, this report is the first step of a follow-up study still in process, in which we confirmed the BD type I intake diagnosis for $100 \%$ of the 32 subjects already evaluated by semistructured interviews. Also it is important to note that effects of past psychiatric history, treatment and comorbid disorders on improvement at the time of discharge and duration of stay have not yet been analyzed. Furthermore, statistical analysis was not controlled for factors known to impact outcome which is another limitation of this study.

Nevertheless, this is one of the first European studies on acute BD-I in youths with a large sample size $(N=80)$, a high clinical severity, and prolonged 
durations of hospitalizations providing us precise and numerous clinical notes.

\section{Phenomenology of acute adolescent mania}

In this sample, female/male ratio was 1.2 and 31 of the 80 subjects presented a mixed episode. Acute onset of the episode occurred in one-third of the patients and the mean duration of stay was 10 weeks. High rates of psychotic features $(62.5 \%)$ were identified as well as high rates of previous personal and family psychiatric history. Mental retardation was found in 17 of the subjects and they exhibited significantly more manic episodes than mixed ones. In a follow-up study examining an 18 to 20-year-old conscripted male cohort, low premorbid IQ was associated with increased risk of schizophrenia but not with BD [58]. To our knowledge, there is no other study on acute mania phenomenology in adolescents with MR.

The rate of psychotic features in this sample is among the highest rates found in previous studies $(50-60 \%)[9,47,29]$. The mean duration of stay in our sample (10 weeks) is much higher than other studies. Twenty-eight days was the mean duration of hospital stay in an Indian prospective study [29]. These results are consistent with the clinical severity of our BD-I sample. But one should remember that the French mental health system is one of the most advantageous for youth psychiatric care. In most cases, patients can remain hospitalized for the length of time necessary in order to reach improvement. In a recent study exploring the transformation of the length of inpatient mental health treatment for young people in the US, the median length of stay for bipolar children and adolescents fell from 19.9 days in 1990 to 5.6 days in 2000 in community hospitals [12]. This difference probably reflects great differences in free access to care especially between the US and France and should be considered when the US and French studies are compared.

In this sample, previous family history of psychiatric disorder indicated a high rate of affective disorders, both unipolar and bipolar. This result is consistent with most studies on BDs in youth [47]. Similarly, recorded past history of psychiatric disorder tended to be high. Depressive episodes were the most frequent diagnoses in past psychiatric history $(42.2 \%)$. This is not surprising as it had been reported that $20-30 \%$ of depressed children, particularly those with psychosis, a family history of $\mathrm{BD}$ and/or pharmacologically induced mania, eventually develop BD $[17,22,51,52,57]$. Interestingly, $16 \%$ had a previous history of brief psychotic episode, indicating that in youth first episode of bipolarity may be non-specific to mood disorders. The rate of personal history of
ADHD in this sample (3.7\%) is close to the prevalence rate in school-aged children (5-9\%). This result is consistent with prospective studies on bipolar adolescents [23] reporting very few people with a history of ADHD. However, this result should be regarded with caution given the limits of our study. Examining the relationship between ADHD and BD, several authors $[13,28,36]$ indicated only one follow-up study [4] on children with ADHD that reported an increasing rate of concurrent BD between the first and the fourth year of the follow-up (from 11 to $23 \%$ ) and suggesting $\mathrm{ADHD}$ as a risk factor for developing $\mathrm{BD}$. But this result has not been replicated. Investigating the prior juvenile diagnoses in adults with mental disorder among the Dunedin prospective-longitudinal cohort, Kim-Cohen et al. [34] reported that young adult mania diagnosed before 26 years of age was likely to be preceded by conduct and/or oppositional disorder and juvenile depression but not by ADHD.

\section{Socio-cultural factors associated with bipolar disorder in youths}

The comparison of manic and mixed subjects showed that children of immigrants as well as subjects with a low SES had significantly more manic episodes. Given the specificity of immigration in France, we can hypothesize that migrants often have a lower SES. We could test the interaction between these two variables (SES and father's origin) and found that there were highly correlated in our sample $(P=0.0011)$. Even if our setting serves $30-50 \%$ of all Ile-de-France paediatric psychiatric hospitalizations, providing a large representation of ethnic origins, we cannot totally exclude a bias in the recruitment of our hospital. It could also suggest that cultural differences may influence the phenomenology of BD-I in youths. To date, very few studies documented this possibility. Bipolar patients of African origin have been described as having more commonly a unipolar manic course and longer periods with manic rather than depressive symptoms [35]. Furthermore, a recent study, in London, reported that Afro-Caribbean and African ethnic groups were more likely than the White European group to have their first presentation with $\mathrm{BD}$ as a manic episode [33]. In a North-American study on BD-I adolescents, description of the index episode indicated that African-American adolescents had significantly higher YMRS scores and rates of psychotic features than Caucasian adolescents [45]. It would need further investigation to determinate if true ethnic differences in the expression of BD exist or if ethnocentric clinician bias may influence patient assessments. Indeed, we cannot rule out the fact that these results may be the consequence of poor recog- 
nition of mixed states in non-European ethnic groups by European clinicians. Another hypothesis is suggested by a report on family factors that may influence the duration of untreated psychosis among African-Americans. With qualitative methods, Compton et al. [16] showed that among these family members, early psychotic symptoms were often attribued to depression, lack of motivation or relational stressors and moreover that they often decided to seek help only after the emergence of unbearable psychotic symptoms or socially disruptive behaviours.

\section{Predictors of clinical improvement at discharge and lenght of hospitalization}

Given that the French mental health care system allows adolescents to remain in hospital until they reach significant recovery, the current study was able to test variables that best predicted improvement without bias due to low duration of stay as a consequence of economic pressure. A better clinical improvement at discharge was predicted by a higher score on manic symptoms at intake and female sex, whereas psychotic symptoms were associated with longer duration of stay. Even if some of our results on predictors at discharge are consistent with findings in previous studies, one should compare them with caution, given differences in prognosis variables selected and sample phenotypes. Actually, several variables assessing outcome can be found in studies: duration of stay, clinical improvement, duration of index episode, recovery and relapse rates, and weekly subsyndromal symptoms. Furthermore, some studies include children and adolescent with bipolar spectrum disorders, who can be inpatient or outpatient subjects, whereas others evaluate hospitalized adolescent bipolar type I disorder, like in our study. To compare our results, we found few prospective studies, including clinical samples and a single community study, that focused on and recruited actively ill BD-I subjects with classic manic elation and/or grandiosity, like our sample [5, 18, 26, 29, 39, 50, 52]. Strober et al. [52] in a study on the longitudinal course of 54 adolescent inpatients with BD-I, showed that the length of time to obtain remission was shorter for manic subjects compared with mixed ones. Possibly, there is a better response to mood stabilizators in pure manic episodes compared to mixed episodes in adolescents. In a study [29] that included 25 youths with BD-I, the presence of a previous affective episode was the only predictive factor of recovery, and was associated with a longer duration of index episode. Birmaher et al. [5], in a 2year follow-up study of 263 children and adolescents with bipolar spectrum disorders, identified several variables associated with prognosis. The authors showed that lower recovery rates (poorer outcome) were associated with lower SES, very early onset (in childhood), longer duration of mood symptoms and psychosis. In our study, psychosis was also associated with poorer outcome (longer duration of stay), but we did not find any association between SES and the two prognosis variables we chose. Delbello et al. [18] examined the 12-month outcome of a sample, that ressembles ours, which included 71 adolescents with BD following first hospitalization for manic or mixed episode (BDI). Consistent with Birmaher's study [5], they found that lower SES predict a poorer syndromic recovery. This difference may be due to economic pressure on length of inpatient stay in the US. Furthermore, they found that co-occurring anxiety disorder, disruptive disorder and ADHD were associated with lower rates of syndromic recovery. In our study, we could not test the impact of comorbid disorders on short-term outcome because of the methodological limitations. In Delbello's et al. [18] study, male sex was associated with higher symptomatic recovery rates, whereas in our study, female sex was associated with a better clinical improvement. Finally, it is to be noticed that, like in our study, most bipolar adolescents experienced syndromic recovery following their first hospitalization for a manic or mixed episode.

\section{Conclusion}

The current study on the phenomenology and shortterm predictive factors of adolescent BD-I episode suggests that (1) severe episodes of BD-I in adolescent usually improve during prolonged inpatient care and (2) socio-cultural factors and MR should deserve more attention and research in youth with BD.

\footnotetext{
Acknowledgments This study was funded by grants from the French Ministry of Health (Programme Hospitalier de Recherche Clinique AOM 06-088) and the Fondation Wyeth pour la Santé de l'Enfant et de l'Adolescent. AC was partly supported by SanofiSynthélabo France through a grant awarded for her PhD research on the outcome of bipolar type 1 disorder in adolescents. We thank Professor Boris Birmaher from Pittsburg University for his helpful comments on an earlier version of the manuscript.
} 


\section{References}

1. Akiskal HS (1995) Developmental pathways to bipolarity: are juvenileonset depressions pre-bipolar? J Am Acad Child Adolesc Psychiatry 34:754763

2. Axelson D, Birmaher B, Strober M, Kay M, Valeri S, Chiappetta L, Ryan N, Leonard H, Hunt J, Iyengar S, Bridge J, Keller M (2006) Phenomenology of children and adolescents with bipolar spectrum disorders. Arch Gen Psychiatry 63:1139-1148

3. Bashir M, Russell J, Johnson G (1987) Bipolar affective disorder in adolescence: a 10-year study. Aust N Z J Psychiatry 21:36-43

4. Biederman J, Faraone S, Mick E et al (1996) Attention-deficit hyperactivity disorder and juvenile mania: an overlooked comorbidity? J Am Acad Child Adolesc Psychiatry 35:997-1008

5. Birmaher B, Axelson D, Strober $\mathrm{M}$ et al (2006) Clinical course of children and adolescents with bipolar spectrum disorders. Arch Gen Psychiatry 63:175183

6. Brief Psychiatric Rating Scale (BPRS) Overoll JE, Gorham DR (1962); traduction française Pichot, 1973

7. Calderoni D, Wudarsky M, Bhangoo R et al (2001) Differentiating childhoodonset schizophrenia from psychotic moood disorders. J Am Acad Child Adolesc Psychiatry 40:1190-1196

8. Carlson GA, Strober M (1978) Manic depressive illness in early adolescence: a study of clinical and diagnostic characteristics in six cases. J Am Acad Child Psychiatry 17:138-153

9. Carlson GA, Fennig S, Bromet EJ (1994) The confusion between bipolar disorder and schizophrenia in youth: where does it stand in the 1990s? J Am Acad Child Adolesc Psychiatry 33:453-460

10. Carlson GA, Bromet EJ, Sievers S (2000) Phenomenology and outcome of subjects with early- and adult-onset psychotic mania. American Journal of Psychiatry 157:213-219

11. Carlson GA (2005) Early onset bipolar disorder: clinical and research considerations. J Clin Child Adolesc Psychol 34:335-345

12. Case BG, Olfson M, Marcus SC, Siegel C (2007) Trends in the inpatient mental health treatment of children and adolescents in US community hospitals between 1990 and 2000. Arch Gen Psychiatry 64:89-96

13. Charfi F, Cohen D (2005) Trouble hyperactif avec déficit de l'attention et trouble bipolaire sont-ils liés? Neuropsychiatrie de l'enfance et de l'adolescence 53:121-127
14. Chen YW, Dilsaver SC (1995) Comorbidity of panic disorder in bipolar illness: evidence from the Epidemiologic Catchment Area Survey. Am J Psychiatry 152:280-282

15. Clinical Global Impressions (CGI ) In: Guy W, Bonato RR (eds) (1970) Manual for the ECDEU Assessment Battery, 2nd Rev edn. National Institute of Mental Health, Chevy Chase, pp 12-112-6

16. Compton MT, Kaslow NJ, Walker EF (2004) Observations on parent/family factors that may influence the duration of untreated psychosis among African American first-episode schizophreniaspectrum patients. Schizophr Res 68:373-385

17. Consoli A, Soultanian C, Tanguy ML, Laurent C, Perisse D, Luque R, Berrios GE, Cohen D (2007) Cotard's syndrome in adolescents and young adults is associated with an increased risk of bipolar disorder. Bipolar Disord 9:1-4

18. Delbello MP, Hanseman D, Adler CM et al (2007) Twelve-month outcome of adolescents with bipolar disorder following first hospitalization for a manic or mixed episode. Am J Psychiatry 164:582-590

19. Diagnostic Inteview for Genetic Studies (DIGS) Nurnberger et al (1994); traduction française C. Laurent (French translation Claudine Laurent)

20. Ernst CL, Goldberg JF (2004) Clinical features related to age at onset in bipolar disorder. J Affect Disord 82:2127

21. Global Assessment of functioning Scale (GAF) Endicott J, Spitzer RL, Fleiss J et al (1976); traduction française J. D. Guelfi et al (1989)

22. Geller B, Fox LW, Clark KA (1994) Rate and predictors of prepubertal bipolarity during follow-up of 6 to 12-year old depressed children. J Am Acad Child Adolesc Psychiatry 33:461-468

23. Geller B, Williams M, Zimmerman B, Frazier J, Beringer L, Warner KL (1998) Prepubertal and early adolescent bipolarity differentiate from ADHA by manic symptoms, grandiose delusions, ultra-rapid or ultraradian cycling. J Affect Disord 51:81-91

24. Geller B, Zimerman B, Williams M, Delbello MP, Bolhofner K, Craney JL, Frazier J, Beringer L, Nickelsburg MJ (2002) DSM-IV mania symptoms in a prepubertal and early adolescent bipolar disorder phenotype compared to attention-deficit hyperactive and normal controls. J Child Adolesc Psychopharmacol 12:11-25
25. Geller B, Sun K, Zimerman B, Luby J, Frazier J, Williams M (1995) Complex and rapid-cycling in bipolar children and adolescents: a preliminary study. J Affect Disord 34:259-268

26. Geller B, Tillman R, Craney JL, Bolhofner K (2004) Four-year prospective outcome and natural history of mania in children with a prepubertal and early adolescent bipolar disorder phenotype. Arch Gen Psychiatry 61:459-467

27. Geller B et al (2002) Two-year prospective follow-up of children with prepubertal and early adolescent bipolar phenotype. Am J Psychiatry 159:927-933

28. Harrington R, Myatt T (2003) Is preadolescent mania the same condition as adult mania? A british perspective. Biol Psychiatry 53:961-969

29. Jairam R, Srinath S, Girimaji SC, Seshadri SP (2004) A prospective 4-5 year follow-up of juvenile onset bipolar disorder. Bipolar Disord 6:386-394

30. Joyce PR (1984) Age of onset in bipolar affective disorder and misdiagnosis as schizophrenia. Psychol Med 14:145149

31. Judd L, Akiskal H, Schettler P, Endicott J (2002) The long-term natural history of the weekly symptomatic status of bipolar I disorder. Arch Gen Psychiatry 59:530-537

32. Judd L, Akiskal H, Schettler P et al (2003) The comparative clinical phenotype and long-term longitudinal episode course of bipolar I and II: a clinical spectrum or distinct disorders? J Affect Disord 73:19-32

33. Kennedy N, Boydell J, van Os J, Murray RM (2004) Ethnic differences in first clinical presentation of bipolar disorder: results from an epidemiological study. J Affect Disord 83:161-168

34. Kim-Cohen J, Caspi A, Moffitt T et al (2003) Prior juvenile diagnoses in adults with mental disorder. Arch Gen Psychiatry 60:709-717

35. Kirov G, Murray RM (1999) Ethnic differences in the presentation of bipolar affective disorder. Eur Psychiatry 14:199-204

36. Klein R, Pine DS, Klein DF (1998) Resolved: mania is mistaken for ADHD in prepubertal children. Negative. J Am Acad Child Adolesc Psychiatry 37:1093-1096

37. Kraepelin E (1921) Manic depressive insanity and paranoia. E \& S Livingstone, Edinburgh

38. Kramlinger KG, Post RM (1996) Ultrarapid and ultradian cycling in bipolar affective illness. Br J Psychiatry 168:314-323 
39. Lewinsohn PM, Klein DN, Seeley JR (1995) Bipolar disorders in a community sample of older adolescents: prevalence, phenomenology, comorbidity, and course. J Am Acad Child Adolesc Psychiatry 34:454-463

40. Leibenluft E, Charney DS, Towbin KE, Bhangoo RK, Pine DS (2003) Defining clinical phenotypes of juvenile mania. Am J Psychiatry 160:430-437

41. Lish JD, Dime-Meenan S, Whybrow PC, Price RA, Hirschfeld RM (1994) The National Depressive and Manicdepressive Association (DMDA) survey of bipolar members. J Affect Disord 31:281-294

42. Luckasson R, Borthwick-Duffy S, Buntix W et al (2002) Mental retardation: definition, classification, and systems of supports, 10th edn. AAMR, Washington, DC

43. McElroy SL, Strakowski SM, West SA, Keck PE Jr, Mc Conville BJ (1997) Phenomenology of adolescent and adult mania in hospitalized patients with bipolar disorder. Am J Psychiatry 154:44-49

44. O'Dowd A (2006) NICE issues new guidance to improve the treatment of bipolar disorder. Br Med J 29

45. Patel NC, Delbello MP, Keck PE, Strakowski SM (2005) Ethnic differences in maintenance antipsychotic prescription among adolescents with bipolar disorder. J Child Adolesc Psychopharmacol 15:938-946
46. Patel NC, Delbello MP, Keck PE, Strakowski SM (2006) Phenomenology associated with age at onset in patient with bipolar disorder at their first psychiatric hospitalization. Bipolar Disord 8:91-94

47. Pavuluri MN, Birmaher B, Naylor MW (2005) Pediatric bipolar disorder: a review of the past 10 years. J Am Acad Child Adolesc Psychiatry 44:846-871

48. Perlis RH, Miyahara S, Marangell LB, Wisniewski SR, Ostacher M, Delbello MP, Bowden CL, Sachs GS, Nierenberg AA (2004) Long-term implications of early onset in bipolar disorder: data from the first 1000 participants in the systematic treatment enhancement program for bipolar disorder (STEPBD). Biol Psychiatry 55:875-881

49. Schurhoff F, Bellivier F, Jouvent R, Mouren-Simeoni MC, Bouvard M, Allilaire JF, Leboyer M (2000) Early and late onset bipolar disorders: two different forms of manic-depressive illness? J Affect Disord 58:215-221

50. Srinath S, Janarolha N, Reddy YC, Girimani SR, Seshadri SR, Subbakrishna DK (1998) A prospective study of bipolar disorder in children and adolescents from India. Acta Psychiatr Scand 98:437-442

51. Strober M, Carlson G (1982) Bipolar illness in adolescents with major depression. Arch Gen Psychiatry 39:549-555
52. Strober M, Schmidt-Lackner S, Freeman R, Bower S, Lampert C, DeAntonio M (1995) Recovery and relapse in adolescents with bipolar affective illness: a five-year naturalistic, prospective follow-up. J Am Acad Child Adolesc Psychiatry 34:724-731

53. Strober M, Birmaher B, Ryan $\mathrm{N}$ et al (2006) Pediatric bipolar disease: current and future perspectives for study of its long-term course and treatment. Bipolar Disord 8:311-321

54. Swanson JM, Sergeant JA, Taylor E et al (1998) Attention-deficit hyperactivity disorder and hyperkinetic disorder. Lancet 351:429-433

55. Taieb O, Flament M, Chevret $S$, Jeammet P, Allilaire J-F, Mazet P, Cohen D (2002) Clinical relevance of electroconvulsive therapy (ECT) in adolescents with severe mood disorder:evidence from a follow-up study. Eur Psychiatry 17:206-212

56. Young RC, Biggs JT, Ziegler VE, Meyer DA (1978) A rating scale for mania: reliability, validity and sensitivity. $\mathrm{Br} \mathrm{J}$ Psychiatry 133:429-435

57. Yung AR, Mc Gorry PD (1996) The initial prodrome in psychosis: description and qualitative aspects. Aust N Z J Psychiatry 30:587-599

58. Zammit S, Allebeck P, David A, Dalman C et al (2004) A longitudinal study of premorbid IQ score and risk of developing schizophrenia, bipolar disorder, severe depression and other nonaffective psychoses. Arch Gen Psychiatry 61:354-360 